\title{
OPERATION FOR THE REMOVAL OF THE ABNORMAL LABII FRENUM SUPERIORIS
}

\author{
By Cakl O. Engstrom, D.D.S., Sacrimento, Cal.
}

$\mathrm{T}$

HIS operation for the removal of an abnormal labii frenum was given in substance before the Pacific Coast Orthodontic Society in 1914. The fol lowing account of the technic is herein described more exactly, being illustrated by an actual case in practice. In contradistinction to other means this operation exemplifies the principle of complete removal of part of the frenum, following certain definite steps and the consequent definite degree of successful result. While confined to the one class of cases, other characteristics of attachment of the frenum would necessarily alter somewhat the technic of the operation presented and this much is left to the judgment of the operator.

Doctor Martin Dewey cites three classes of the abnormal frenum affecting the positions of the upper teeth.* First, that in which the central incisors are equidistant apart throughout their axial length as shown in Fig. 1 ; second, that in which the central incisors diverge toward the incisal region as shown

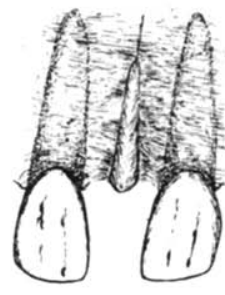

Fig. 1.

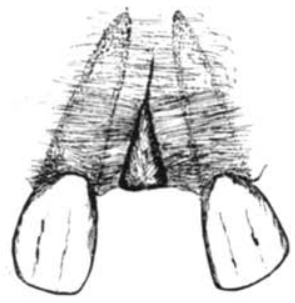

Fig. 2.

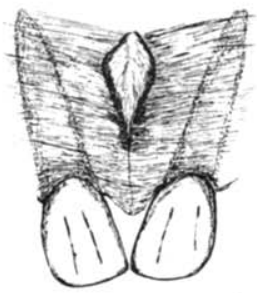

Fig. 3.

in Fig. 2; and, third, that in which the central incisors diverge in the direction of the apical portion of the roots as shown in Fig. 3 .

The abnormal frenum mentioned above, as of Class 1 , is ustually present and the following description deals principally with that form. A photograph of the case is shown in Fig. 4. The frenum being more extended does not show the fullness as shown in Fig. 5. It will be noted that the lateral incisors have not erupted and the child is seven and one-half years of age.

An appliance of bands, vertical tubes and pins, and .022 wire was first constructed and adjusted as shown in Fig. 5. By this means pressure was exerted and the central incisors were moved mesially, but not into contact with each other. This was done to promote osteogenetic action. The wire with pins attached was then removed and the following day the operation for the removal of the abnormal frenum was performed.

In Figs. 6 and 7 the incisions are marked. A local anesthetic was used. By means of a cataract knife, incision $a$ to $b$ was made alongside of the frenum, this isstre.

*See article by Dr. Martin Dewey, entitled "Three Types of Frenum Labiorum," on page 461 of 
leaving a thin covering of tissue next to the tooth. Beginning this incision, the point of the knife was placed at a point on the process designed to be the inferior extremity of attachment of the frenum following the operation. The cut was made straight down to the bone and extended back to a line tangent to the cingula of the central incisors. Another incision was made similar to $a-b$ on

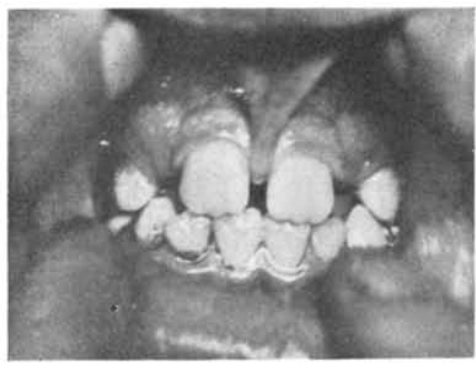

Fig. 4.

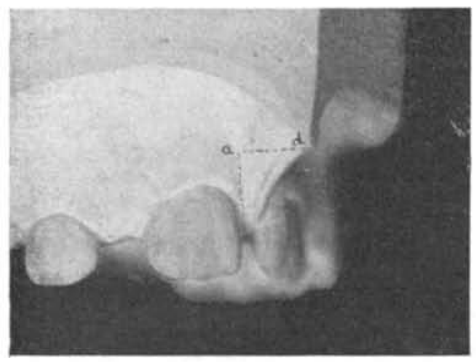

Fig. 6.

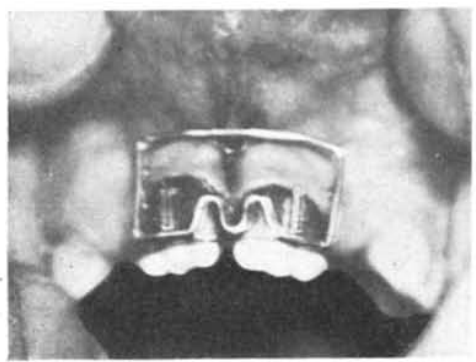

Fig. 8.

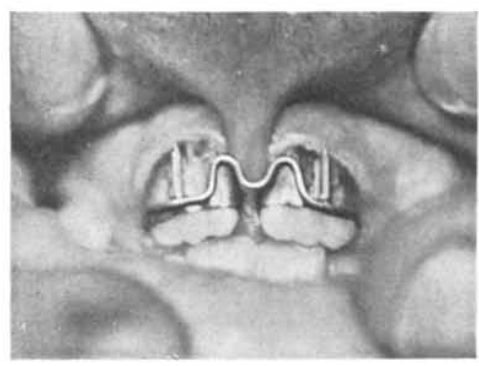

Fig. 5.

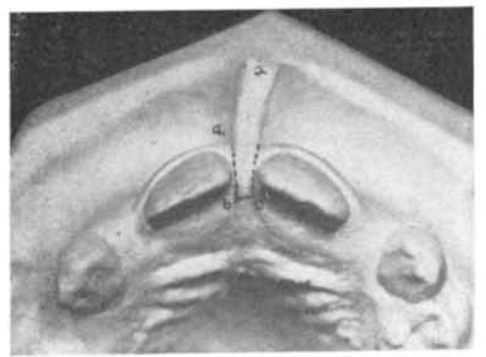

Fig. 7.

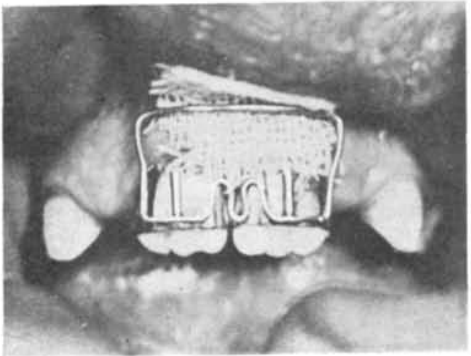

Fig. 9.

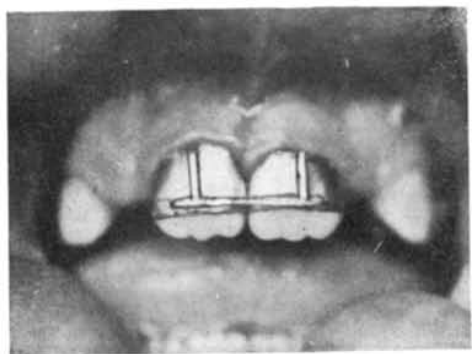

Fig. 10. 
the other side of the frenum ending at $c$. With the end of the cataract knife the fibers of the frenum were severed from their bony attachment, beginning with incision $c$ to $b$. As this was done the frenum was withdrawn from between the teeth by tension, effected by holding the lip. The fibers were found to be attached up as far as the point $a$. The fibers having been severed, and the tension on the frenum being thereby released, the frenum retracted and stood out from the lip but a comparatively short distance. This part of the frenum $d$ to $a$ was then severed from the lip with a pair of small scissors. No tension was exerted on this part of the frenum in the cutting and as a rule no stitches are necessary. A wire was added to the ends of that shown in Fig. 5 and illustrated in Fig. 8. Adjustment was made to move the central incisors into juxtaposition. The illustration is not quite distinct due to movement of the patient during the photographing. A piece of gauze was doubled and placed under the wire extension as shown in Fig. 9. A one-half per cent solution of chlorazine (Abbott) was flowed over the gauze and incisions, and as the lip was released

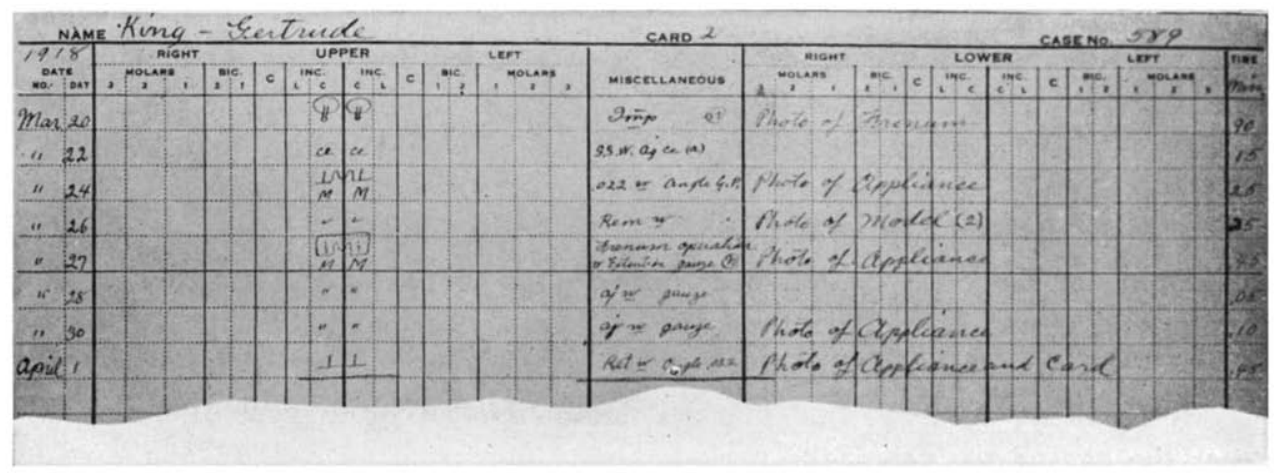

Fig. 11.

the gauze was folded preventing a reattachment of the tissues. Instructions were given regarding the cleaning of the gatuze and cut surfaces with a onehalf per cent solution of chlorazine before and after meals and at bed time, using a water syringe.

Fig. 10 shows wound healed and teeth in proper position with retaining wire. The retaining wire is to be removed when proper support is attained from other teeth.

Fig. 11 is an illustration. of the record of treatment. The bands, tubes, wires, and their positions are shown. Under heading "Miscellaneous," the $n$ encircled designates notes on the reverse side of the card. On March 27 movement of the teeth bodily and mesially is designated by the letter $m$. It is presumed the other markings will be understood by reference to the description given above. On account of the photographs being taken, more time is recorded than would otherwise be necessary.

This operation commends itself because of its definite procedure and results, its simplicity and the short time in which it may be performed. As a rule the little patient is not cognizant of what is being done. 